\title{
PREJOB BRIEFING USING PROCESS DATA AND TAG-OUT / LINE-UP DATA ON 2D DRAWINGS
}

\author{
FRANÇOIS DIONIS $^{1 *}$, RIBIERE ALAIN ${ }^{1}$, AUBIN RENAUD $^{1}$, and CATTEAU ROMAIN ${ }^{2}$ \\ ${ }^{1}$ EDF/R\&D, STEP Department, 78401 Chatou, France \\ ${ }^{2}$ Thalès Services, 78141 Vélizy Vélizy, France \\ "Corresponding author. E-mail : francois.dionis@edf.fr
}

Invited September14, 2011

Received November 01, 2011

Accepted for Publication February 27, 2012

This paper discusses the concept of merging multiple sources of data on the same 2D CAD drawing(s) for power plant operation. It also presents the concepts and tools used in this project.

KEYWORDS : Prejob Briefing, Process Data, Tag-in, Tag-out, 2D Drawing, Database, Operation.

\section{USING 2D TECHNOLOGY TO PROVIDE ADVANCED OPERATION SUPPORT TOOLS}

Today, 2D CAD technology is commonly used in the processes of plant design, with extended functionalities and multiple links with databases and 3D tools. But for plant operation, the drawings are commonly used as paper documents, not as an advanced computerized support for operation and maintenance activities.

This paper presents the results of a research project, trying to bridge the gap between design and operation, using the same 2D technology, with the aim of providing advanced aids for plant operation and maintenance.

\section{CAD DRAWINGS}

\subsection{Existing Drawings Versus New Drawings}

In a large majority of plants, CAD drawings (P\&ID, electrical diagrams, mechanical drawings, and so on) are now difficult to modify, due to the obsolescence of their support software. The question then becomes: should we convert the existing CAD drawings to new formats or should we redevelop new sets of CAD drawings to reach standards? The answer to this question will depend mainly on the following criteria: what is the format of the existing CAD drawings ( $\mathrm{P} \& \mathrm{ID}$, Electrical, diagrams, and so on)? Is it more economical to convert/update the existing drawings or to redevelop new CAD drawings? Either option should be viable.

\subsection{A Generic 2D CAD Format Developed by EDF}

At EDF rather than transferring existing 2D CAD drawings directly into new software, we have decided to first replace a part of the existing out of date CAD system with a more up to date open system (named 2D NGC Kernel). Our engineering division has thus opted to re-use existing CAD drawings and import them into the new software solution. The new format is a free XML format, called NGC ("Noyau Génerique de CAO"). The structure of an XML NGC file is composed of two sections:

- the first section includes the definition of the business objects and all their relationships, for example the pipes and the valves as well as the link between the two;

- the second section includes the definition of the graphical elements (primitives) representing the visible part of the drawings (curves, lines, and so on).

This format is completely generic and therefore independent of the CAD software used.

With XML transformations or file format transformations, it is also possible to recover specific drawings and export them in a "kind-of" NGC format. Then, the developed concept is not only applicable to EDF, it is also valid for other companies when they use published CAD software formats. See diagram below.

The advantage of the EDF approach is that the solution is very generic, independent of the type of drawings (P\&ID,

\footnotetext{
${ }^{1}$ NGC means « Generic CAD Kernel ».
} 

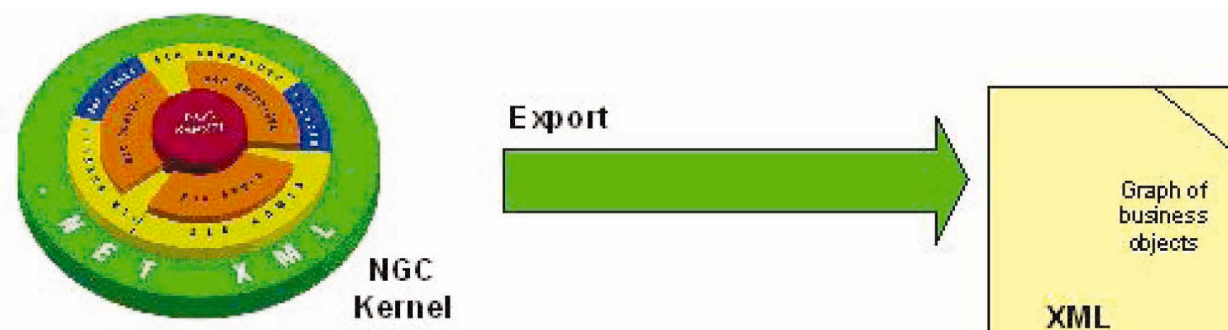

XML

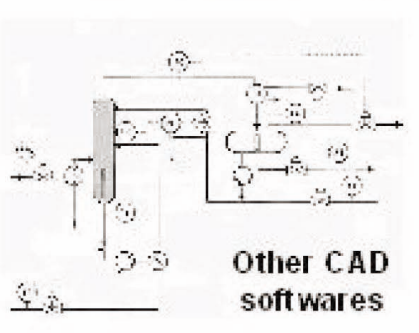

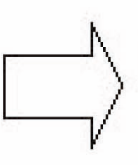

soft wares
NGC File

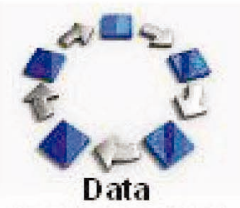

transformation

Fig. 1. A Generic 2D CAD Format.

mechanical, electrical, I\&C...) and the type of format which makes the solution more adaptable to different types of business and also more economic.

The graphical editor at the base of the architecture is AutoCAD, which can also export the drawings in standard formats if needed. In a long term vision, AutoCAD can easily be replaced by another edition software, without significant modification of the CAD architecture.

\section{LINKING THE CAD BUSINESS OBJECTS TO OTHER SOURCES OF DATA}

\subsection{The Business Objects are Central}

With the NGC format, each business object is now part of the drawings, and can be linked to an operation database ${ }^{2}$ (such eSOMS, Maximo or Asset-Suite) or linked to process data provided by the Instrumentation and Control (I\&C) system.

As an example, a valve, a switch, a pump, a pipe, etc. is displayed on drawings as an object, but also displayed in the database as a record, the two being linked. Therefore, the link between the CAD world and the database world can be easily established.

As a second example, each process data, provided by the I\&C system, is also a kind of business object. Thus, it becomes possible to directly and automatically access it to process data from the CAD drawings. This is the case for P\&ID, but also for electrical, mechanical or I\&C drawings.

\footnotetext{
${ }^{2}$ These databases, dedicated to operation and / or maintenance are
} called EAM (Enterprise Asset Management) solutions.

\subsection{Overview of the Architecture}

In order to easily promote the new operation tools using 2D drawing and operation data, a specific software architecture has been developed by EDF/R\&D. The idea is to allow end users to interact graphically with operation and maintenance data, and to access different sources of data: EAM, process data, outage schedule, etc.

The "foundation" of this architecture is named GEL (Graphical Enhancement Library).

Each application based on GEL has to manage its interactions with data input or outputs. For example, the alignment procedures and clearances module (Tag-Out) manages its interface with an EAM (or potentially with any other source of data) and with a 2D documents server.

GEL provides several common services to the final applications. GEL:

- reads XML NGC files,

- transforms the XML files into SVG format for visualization,

- transforms the XML files into a graph of business objects,

- permits visualization,

- permits interaction with graphical primitives to reach business objects,

- offers a set of primitives for graphical enhancement,

- enables users to export enhanced drawings (image file, SVG, PDF).

The first application developed and industrialized by EDF on the basis of GEL is a generic module of drawing visualization. It is already used for P\&ID and room drawings visualization.

This module has now been updated. It can, with the GEL technology, access alignment procedures and clearance data, and show the position of the equipments, over the P\&ID drawing. 


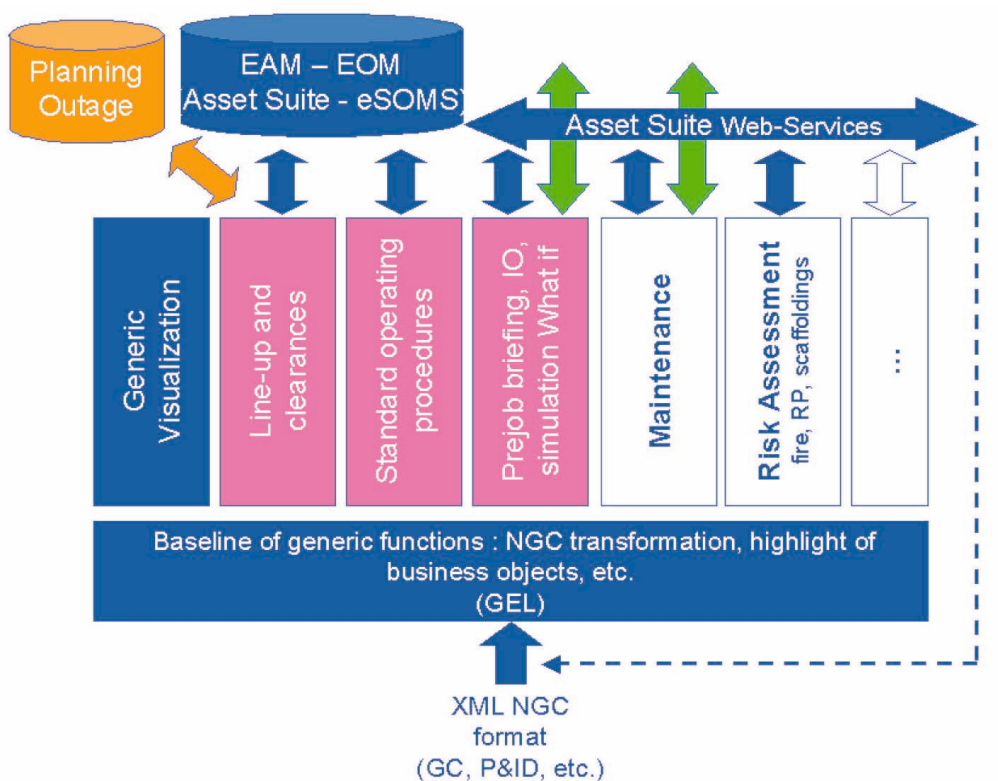

Fig. 2. An Open Architecture for Linking 2D CAD Files to Multiple Sources of Data

\section{Creation of line-up procedures using the EAM to manage its life cycle (1D)}

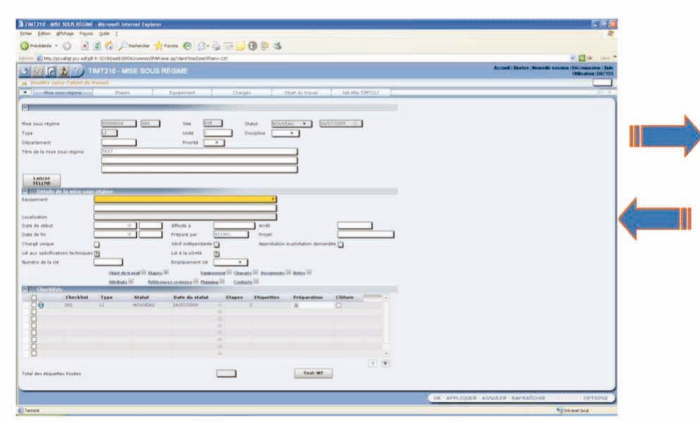

(3) to follow the process workflow
(2) Graphically modify the line-up procedures once created with the EAM database

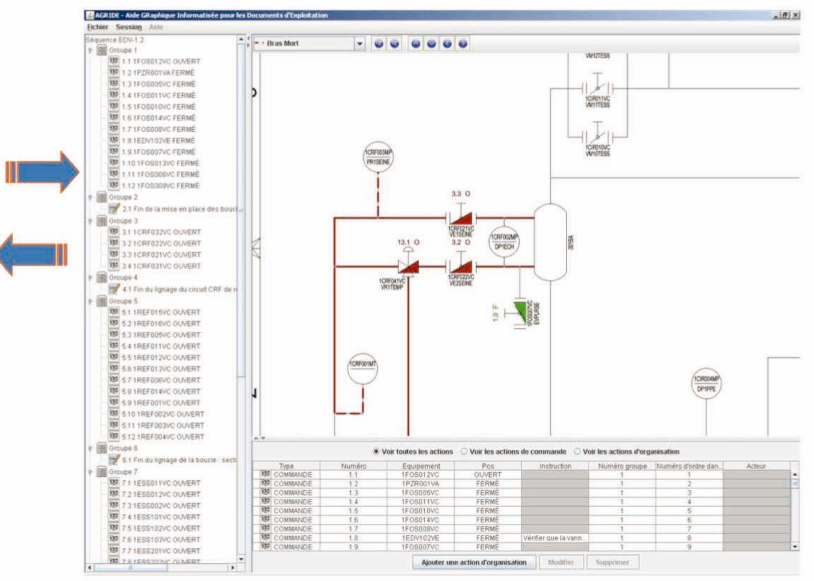

Fig. 3. Graphically Modifying Operation Documents.

Based on the same idea, an application for the enhancement of plant room drawings (e.g., for radioprotection, maintenance, risks management, etc.) has been developed.

\section{PREPARING CLEARANCES AND ALIGNMENTS ON DRAWINGS}

An important area of improvement is the ability to view or modify operation and/or maintenance processes (alignment checklists, clearances, radiations zones, scaffoldings, chemical risks, etc.) directly on 2D drawings.
Plant operation and/or maintenance data (work orders, tag out, etc.) are generally stored and managed in an EAM database. The 2D "plug in" developed on GEL enables viewing and/or modifying of the operation/maintenance data (at each steps of the workflow) from the EAM using the $2 \mathrm{D}$ drawing.

At EDF R\&D, we have demonstrated that such a concept is both valuable and feasible. We have developed a prototype that enables users to graphically modify alignment checklists or tag-out created in Asset Suite or eSOMS directly from a drawing. From Asset Suite or eSOMS, the user can directly access and display a graphical 


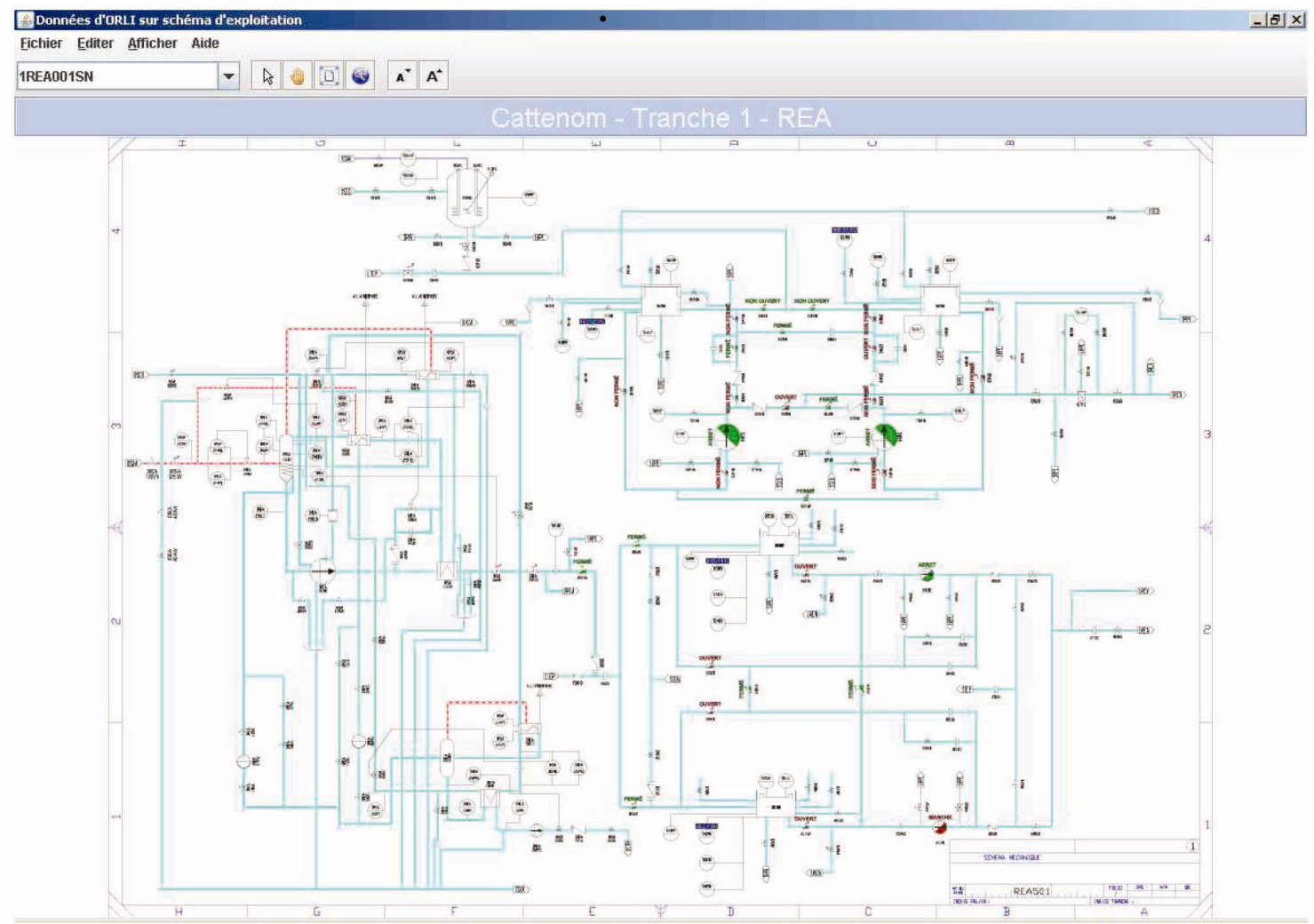

Fig. 4. Process Data on P\&ID.

representation of the tag-out or alignment checklist: position of valves, state of pumps, state of flows, etc. Once graphically displayed, the tag-out or checklist can then be modified directly onto the drawing. Once done, the user can then return to Asset Suite or eSOMS and any modifications made on the drawing are automatically transferred to Asset Suite or eSOMS.

The figure below shows how using the "graphical plug-in" a user can switch from Asset Suite to the drawing. An online help option will guide the user on how to use the $2 \mathrm{D}$ drawing interface as well as understand the type of data required.

This application allows the setting of the position of equipments, highlighting the involved pipes, drawing temporary pipes, adding comments, etc., in order to prepare line-up procedures, clearances or normal operation procedures. It also provides additional features such a proposal of the "clearance bubble", reverse of the alignment procedures, grouping of actions, ordering of actions to perform, definition of the actor (field operator, clearances officer, operator) who will perform the action, etc. Standard helps such as navigation through drawings, search of equipments, copy and paste of documents, generation of paper procedures, print of enhanced drawings, etc. are also available.

\section{VIEWING AND ACCESSING PROCESS DATA ON P\&IDS}

Once the clearances and the alignments have been prepared on P\&IDs, it is very useful, just before performing the required actions in the field, to check if the state of the plant is really compliant with them. Then, we had the idea to show, on the P\&ID, both information from the state of equipments due to the preparation, and the real state of the plant provided by the I\&C system. Thus, on the same drawing, it becomes easy to detect any potential discrepancy.

Process data can be analog values or logical values. The analog values are directly presented above the sensors in tags. The tags can be moved by the user, in order to avoid having hidden information on the drawing.

For each process value, it is possible to access the computer output, to have access to more information.

Additional features are provided, such as access to data historian for each value, or comparison between different power plants, for example, in order to optimize the process.

The process data shown by the application can be filtered by type, elementary system or directly selected in a list of available values. 


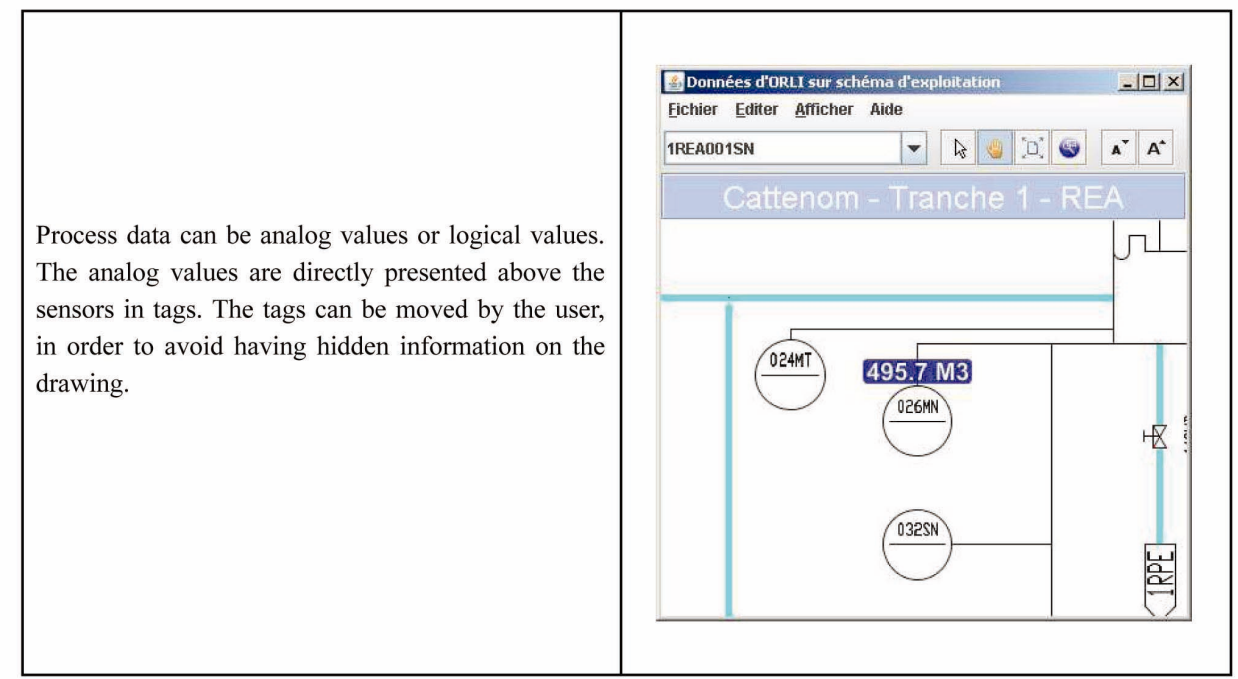

Fig. 5. Analog Values.

The logical values change the appearance of the monitored equipments, in the same manner as the preparation of operation documents.

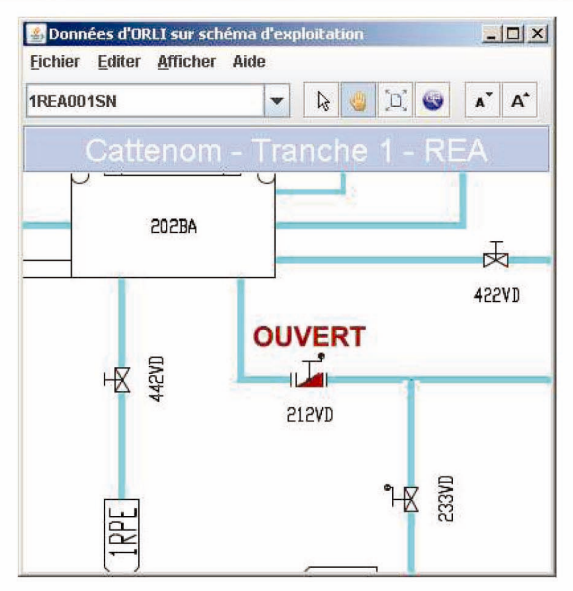

Fig. 6. Logical Values.

Additional features are provided, such as access to data historian for each value, or comparison between different power plants, for example, in order to optimize the process.

The process data shown by the application can be filtered by type, elementary system or directly selected in a list of available values.

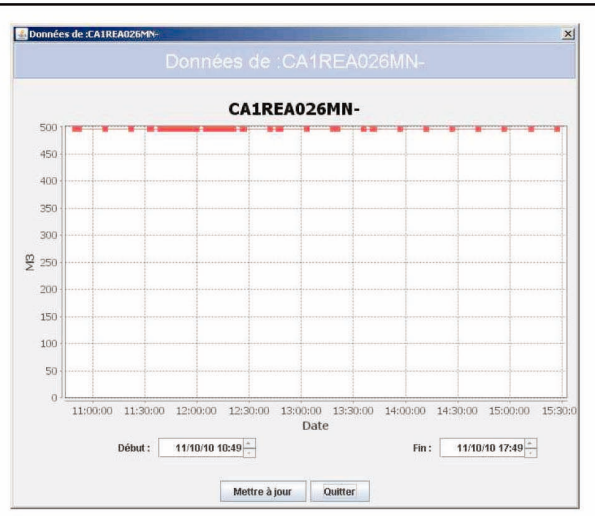

Fig. 7. Direct Access to Data Historian. 


\section{WORKING IN A RAPID APPLICATION DESIGN MODEL}

\subsection{Working with end users}

\subsubsection{Paper Title}

The first $R \& D$ prototype was developed in our $R \& D$ lab in Chatou (Paris) over a period of about six months. Continuous improvements were made during that period based on the feedback of end user testing. Clearances managers as well as field operators were used during that period for the testing. After the testing period, it was decided to move the prototype to one site and see how it would perform under real conditions. The Penly Nuclear Power Plant (1300 MW) near Dieppe (North of France) was selected as the pilot project. Today the prototype has been deployed and is being used by the Penly plant personnel (mostly clearance managers and field operators) to create/modify/visualize clearances and alignment checklist using the graphical interface. Alignment checklists have been graphically created for eight elementary systems. The module dedicated to process data visualization is today under test in Penly.

\subsection{Working with the Software Supplier}

An important effort has been to standardize the data exchange interface between the R\&D prototype and the Ventyx software in order to be able to interact with both the Ventyx EAM (Asset Suite Tagout) and EOM (eSOMS Checklist) solutions. Web Services have been developed and used with Asset Suite. However the interface with eSOMS is based on an XML file. We expect to reuse the Asset Suite Web Services in future development of the Web Version of the eSOMS interface.

The development and improvement of the prototype is continuing this year. Additional interfaces are currently being developed that will bring together clearances and alignment checklist into one graphical view. Using Asset Suite, all conflicts will be resolved and a final validation will be done using the graphical visualization.

\section{ACKNOWLEDGEMENT}

Special thanks to our colleagues from the Penly 1300 MW NPP, who have strongly been involved in this project.

Many thanks to Pierre Lemercier from the EDF Power Division, who has supported our project since the beginning, at all levels of the company.

\section{REFERENCES}

[1 ] DIONIS F., EDF-R\&D's concept for using 2D drawings as an EAM/EOM solution to create, modify and visualize operation data, ENC 2010 Barcelona, EDF/R\&D.

[2] AUBIN R., Toward the preparation of operation procedures and clearances using 2-D interactive drawings, ANS NPIC \&HMIT 2010, Las Vegas, EDF/R\&D.

[ 3 ] AUBIN R., CATTEAU R., Projet TELL-ME : spécification fonctionnelle d'une librairie d'enrichissement graphique de schéma CAO 2D NGC June 2009, EDF/R\&D.

[4] RIBIERE A., CATTEAU R., Développement d'une application récupérant des données ORLI et les affichant sur un schéma d'exploitation, Novembre 2010, EDF/R\&D. 